\title{
Risk Factors and Case Management of Acute Diarrhoea in North Gondar Zone, Ethiopia
}

\author{
Rishi P. Mediratta',Amsalu Feleke², Lawrence H. Moulton ${ }^{3}$, Sisay Yifru, and R. Bradley Sack ${ }^{3}$ \\ 'Public Health Studies, Johns Hopkins University, Baltimore, MD, USA, ${ }^{2}$ School of Public Health, College of Medicine and Health \\ Sciences, University of Gondar, Gondar, Ethiopia, ${ }^{3}$ Department of International Health, Johns Hopkins Bloomberg School of \\ Public Health, Baltimore, MD, USA, and ${ }^{4}$ School of Medicine, College of Medicine and Health Sciences, \\ University of Gondar, Gondar, Ethiopia
}

\begin{abstract}
In Ethiopia, evidence is lacking about maternal care-taking and environmental risk factors that contribute to acute diarrhoea and the case management of diarrhoea. The aim of this study was to identify the risk factors and to understand the management of acute diarrhoea. A pretested structured questionnaire was used for interviewing mothers of 440 children in a prospective, matched, case-control study at the University of Gondar Referral and Teaching Hospital in Gondar, Ethiopia. Results of multivariate analysis demonstrated that children who were breastfed and not completely weaned and mothers who were farmers were protective factors; risk factors for diarrhoea included sharing drinking-water and introducing supplemental foods. Children presented with acute diarrhoea for 3.9 days with 4.3 stools per day. Mothers usually did not increase breastmilk and other fluids during diarrhoea episodes and generally did not take children with diarrhoea to traditional healers. Incorporating messages about the prevention and treatment of acute diarrhoea into child-health interventions will help reduce morbidity and mortality associated with this disease.
\end{abstract}

Key words: Case-control studies; Case management; Diarrhoea, Acute; Oral rehydration solution; Prospective studies; Risk factors; Ethiopia

\section{INTRODUCTION}

Diarrhoeal disease remains one of the principal causes of morbidity and mortality in children. Globally, children aged less than five years experience, on average, 3.2 episodes of diarrhoea every year (1), and consequently 1.87 million children will die from dehydration associated with diarrhoeal disease (2). The child mortality rate in Ethiopia in 2007 was 199 per 1,000 births (3), and approximately one of every five deaths every year in Ethiopia is due to diarrhoeal disease (2).

Epidemiological studies have been conducted to identify the risk factors that contribute to the incidence of diarrhoeal disease in developing countries; however, to our knowledge, this is the first study in

Correspondence and reprint requests should be addressed to:

Dr. R. Bradley Sack

Department of International Health

Johns Hopkins Bloomberg School of Public Health

615 North Wolfe St, Rm W5035

Baltimore, MD 21205

USA

Email: rsack@jhsph.edu

Fax: (410) 502- 6733
Ethiopia that investigated the environmental and maternal caretaking variables of acute diarrhoea and the management of the illness. Both environmental and maternal caretaking variables are key implementation priorities that are likely to contribute to reduction of mortality due to diarrhoeal disease (3).

Furthermore, managing acute diarrhoea appropriately is critical in preventing dehydration and deaths of children (4). The use of oral rehydration therapy (ORT), ongoing fluid replacement, and age-appropriate nutritional support represent the foundation for the management of acute diarrhoeal illnesses among children (5). The introduction of ORT in the early 1980s dramatically reduced mortality associated with diarrhoeal disease worldwide (6). Nonetheless, the low use-rates of ORT and inadequate knowledge of the preparation of oral rehydration solution (ORS) represent areas of concern regarding the management of acute diarrhoea, particularly in Ethiopia.

The aim of this study was to identify the risk factors and to understand the case management of acute diarrhoeal disease at the University of Gondar Re- 
ferral and Teaching Hospital, which would help develop effective interventions to reduce morbidity and mortality associated with diarrhoeal disease.

\section{MATERIALS AND METHODS}

Study site and design

A prospective, matched, case-control study was conducted at the University of Gondar Referral and Teaching Hospital in the North Gondar Zone, Ethiopia, where the population is more than 2.9 million. Gondar is located approximately $700 \mathrm{~km}$ from Addis Ababa in the northwestern part of Ethiopia called the Amhara region. The average household has five members, often living in one room; many households have domestic animals; over $60 \%$ of the population has access to improved sources of drinking-water; and almost $40 \%$ of the population has access to a toilet or a latrine (7). In the Amhara region, $25 \%$ of females and $54 \%$ of males are literate (7). Three-fourths of health problems faced by children are due to communicable diseases, and at least half of all children aged less than five years experience symptoms of acute respiratory infections, malaria, and diarrhoea at any given point (7). Often, caretakers first take sick children to health posts or to health centres, and the district and zonal hospitals often are the last places where caregivers seek care for sick children. The University of Gondar Referral and Teaching Hospital provides care to approximately 10,000 children every year; 50 of the 350 beds in the hospital are allocated for children.

The sample-size of 220 matched subjects was determined, using a confidence level of $95 \%$ and a power of $80 \%$ to detect a $50 \%$ difference between cases and controls (8). Four hundred and forty cases and controls were enrolled during July 2007-January 2008. Interviews with the mothers of children were completed after verbal informed consent was obtained.

All children, aged less than five years, who came to the hospital for general treatment, were eligible for the study. Upon presentation, children were assessed at the outpatient department (OPD). If they did not have dehydration or complications, they were given prescriptions for medications and/or ORS and discharged. Children with moderate or severe dehydration and/or complications were referred to the inpatient paediatric ward, where they received appropriate drug and supportive therapy. All medical services were paid as out-of-pocket at the hospital, unless free papers were secured from peasant associations or local governments.
Diarrhoea was defined as three or more liquid stools within a 24-hour period. Acute diarrhoea was defined as having diarrhoea for less than 14 days. Cases with acute diarrhoea were consecutively enrolled from the OPD and inpatient paediatric ward. Controls were selected from children who did not present with acute diarrhoea for at least 14 days before the date of interview. Controls from the OPD presented with a range of conditions, such as upper and lower respiratory tract infections, malaria, otitis media, and tonsillitis. Controls from the inpatient ward presented with upper and lower respiratory tract infections, malaria, malnutrition, paediatric HIV/AIDS, tuberculosis, and sepsis. Controls were selected to match the cases with 1:1 ratio by the following criteria: six-month age categories, sex, within two weeks from the date of the case visit, and the same ward. Children were excluded if they were aged five years or older, and children with acute diarrhoea were excluded if they did not meet the clinical definition of acute diarrhoea.

\section{Data collection}

Interviews with the mothers of children enrolled in the study were conducted in Amharic, the local language, by 10 interns who were working in the paediatrics department. All interviewers could read and write English. After the children were examined, data were collected using a pretested structured questionnaire that measured sociodemographic characteristics, nutritional factors, maternal and child hand-washing and disposal of faeces, water and latrine-use, disposal of wastes, and ORS-use. Additionally, the clinical presentation of illness, food and fluid intake, and treatment given by physicians were recorded for all the cases. The level of dehydration of all children was measured according to the criteria of the World Health Organization (WHO) for dehydration using four signs, such as mental status, eyes, thirst, and skin turgor (9). There was no attempt to make an aetiologic diagnosis for cases.

\section{Statistical analysis}

Data were entered in Excel 2002 and analyzed using the Stata software (version 9.0) (StataCorp LP, College Station, TX, USA). A univariate analysis was conducted for all the variables from the questionnaire. Variables with $\mathrm{p}<0.10$ were considered for inclusion in conditional logistic regression, along with variables that were known risk factors, such as income and maternal education $(10,11)$. Multivariate odds ratio (OR) and 95\% confidence intervals (CIs) were calculated from the coefficients from the 
regression model. The final model was determined using forward step-wise logistic regression, which included variables significant at $\mathrm{p}<0.05$, and the sensitivity of this model was checked by including maternal education and income variables in the socioeconomic status (SES)-adjusted model.

\section{Ethical approval}

Ethical clearance was obtained from the Research and Publications Office at the University of Gondar and the Committee on Human Research at the Johns Hopkins Bloomberg School of Public Health.

\section{RESULTS \\ Potential risk factors of acute diarrhoea \\ Sociodemographic characteristics}

In total, 440 children-220 cases and 220 controls-were enrolled in the study. The sociodemographic characteristics are presented in Table 1. Univariate analysis revealed that cases and control groups were similar with respect to most characteristics, including age and sex of children, maternal and paternal illiteracy, and where mothers heard about child-health education. The median age for cases and controls was 15 (range 1-59) months. Significantly associated with protection from diarrhoeal disease were mothers who were farmers and households with monthly income over Birr 99 (US\$ 11).

\section{Nutritional exposure variables}

Results of univariate analysis of nutritional exposure variables showed that children who were breastfed and not completely weaned had half the risk of developing diarrhoea than children who were not breastfed and not completely weaned $(\mathrm{OR}=0.48$, CI $0.28-0.81, p=0.006)$. Further analysis revealed that children, aged 1-6 months, who were breastfed and not completely weaned, had a lower risk of acute diarrhoea ( $7 \%$ cases vs $16 \%$ controls, OR=0.26, CI $0.11-0.60, \mathrm{p}=0.001)$, with the same trend for children aged $13-24$ months (22\% cases vs $29 \%$ controls, OR=0.55, CI 0.31-0.97, $\mathrm{p}=0.039)$. However, children, aged 7-12 months, who were breastfed had a higher risk of diarrhoea (31\% cases vs $22 \%$ controls, $\mathrm{OR}=2.06, \mathrm{CI} 1.17-3.61, \mathrm{p}=0.012)$. Children who started supplemental feeding, defined as food or liquid that was not breastmilk, were 2.70 times more likely to develop diarrhoea than children who had not yet started supplemental feeding (93\% cases vs $86 \%$ controls, CI 1.30-5.57, $\mathrm{p}=0.007$ ).
Children, aged 7-12 months, who received supplemental food had a higher risk of diarrhoea (32\% cases vs $22 \%$ controls, OR=2.69, CI 1.42-5.09, $\mathrm{p}=0.002$ ). There were no differences between the cases and the controls with respect to when supplemental feeding was started, the amount of time children was breastfed, and the presence of bottlefeeding.

\section{Maternal caretaking exposure variables}

The majority of the maternal caretaking exposure variables, presented in Table 2, were not significant in univariate analysis. Cases and controls displayed similar characteristics with respect to hand-washing behaviours, the use of soap, where mothers disposed of stools of children and the water used for washing the stool, and frequency of mother and child changing clothes and bathing. More cases had soap present in their homes than the controls had $(\mathrm{OR}=1.82$, CI 1.01-3.29, $\mathrm{p}=0.047)$.

\section{Water exposure variables}

As shown in Table 3, univariate analysis revealed that households with a protected spring as the water source had a $61 \%$ less risk of developing diarrhoea than households with other water sources $(\mathrm{OR}=0.39$, CI 0.18-0.84, $\mathrm{p}=0.017)$. Tap was the major source of water in the study ( $82 \%$ for cases vs $75 \%$ for controls). Furthermore, children whose families shared the water source with 6-10 households had almost twice the risk of developing diarrhoea than families who had their own water source $(\mathrm{OR}=1.94, \mathrm{CI}$ 1.04-3.63, $\mathrm{p}=0.038)$. Households that stored water in containers with a narrow nozzle were less likely to develop diarrhoea than households that stored water in containers with wide nozzles $(\mathrm{OR}=0.56, \mathrm{CI}$ 0.31-0.98, $\mathrm{p}=0.042$ ). Lastly, the treatment of water was not significant between the cases and the controls and did not correlate with sharing the domestic water source.

\section{Latrine and waste-disposal exposure variables}

Latrine and waste-disposal exposure variables, such as presence of a toilet, type of toilet used, sharing of toilets with other households, and presence of waste-disposal systems, were not significant in univariate analysis. Of households that did not have a toilet, $30 \%$ of the controls compared to $22 \%$ of the cases used an open field to dispose of their stools.

\section{Multivariate regression}

An adjusted multivariate model was created by forward step-wise logistic regression using the factors that were significant with the univariate model and income and maternal education since they are 


\begin{tabular}{|c|c|c|c|c|c|}
\hline Characteristics & $\begin{array}{l}\text { Cases }(\%) \\
(\mathrm{n}=220)\end{array}$ & $\begin{array}{l}\text { Controls }(\%) \\
\quad(\mathrm{n}=220)\end{array}$ & OR & $\mathrm{CI}$ & $\mathrm{p}$ value \\
\hline Age (years) & $1.57(1.01)^{\dagger}$ & $1.51(1.03)$ & Matched & & \\
\hline Male child & 65 & 65 & Matched & & \\
\hline Inpatient & 44 & 44 & Matched & & \\
\hline Persons per household & $4.6(1.8)^{\dagger}$ & $4.6(1.8)$ & 0.98 & $0.87-1.09$ & 0.656 \\
\hline $\begin{array}{l}\text { Children aged }<5 \text { years per } \\
\text { household }\end{array}$ & $1.4(0.55)^{\dagger}$ & $1.3(0.65)$ & 1.05 & $0.76-1.44$ & 0.747 \\
\hline Age (years) of mother & $26(4.8)^{\dagger}$ & $27(5.2)$ & 1.00 & $0.97-1.03$ & 0.995 \\
\hline Age (years) of father & $34(6.4)^{\dagger}$ & $33(6.6)$ & 1.00 & 0.98-1.05 & 0.316 \\
\hline Literate mother & 61 & 56 & 1.20 & $0.84-1.77$ & 0.332 \\
\hline Literate father & 76 & 73 & 1.18 & $0.77-1.82$ & 0.443 \\
\hline \multicolumn{6}{|l|}{ Education of mother } \\
\hline Less than grade 9 & 60 & 68 & 1.00 & & \\
\hline Grade 9 and higher & 40 & 32 & 1.45 & $0.96-2.19$ & 0.080 \\
\hline \multicolumn{6}{|l|}{ Education of father } \\
\hline No formal education & 29 & 35 & 1.00 & & \\
\hline Grade $1-8$ & 23 & 22 & 1.29 & $0.77-2.13$ & 0.322 \\
\hline Above Grade 8 & 47 & 43 & 1.33 & $0.85-2.1$ & 0.208 \\
\hline Unknown & 1 & 0 & 2.37 & $0.26-26.94$ & 0.485 \\
\hline \multicolumn{6}{|l|}{ Marriage } \\
\hline Married & 89 & 94 & 1.00 & & \\
\hline $\begin{array}{l}\text { Divorced, separated, } \\
\text { widowed }\end{array}$ & 9 & 5 & 2.11 & $0.95-4.67$ & 0.065 \\
\hline Never married & 2 & 1 & 1.33 & $0.30-5.96$ & 0.300 \\
\hline \multicolumn{6}{|l|}{ Birth order } \\
\hline $1-3$ & 85 & 81 & 1.00 & & \\
\hline $4-5$ & 10 & 14 & 0.65 & $0.35-1.19$ & 0.166 \\
\hline$>6$ & 5 & 5 & 0.82 & $0.34-1.96$ & 0.657 \\
\hline \multicolumn{6}{|l|}{ Ethnicity } \\
\hline Amhara & 96 & 95 & 1.00 & & \\
\hline Non-Amhara & 4 & 5 & 0.72 & $0.29-1.81$ & 0.493 \\
\hline \multicolumn{6}{|l|}{ Occupation of mother } \\
\hline $\begin{array}{l}\text { Government employ- } \\
\text { ment }\end{array}$ & 31 & 26 & 1.00 & & \\
\hline Daily labour & 15 & 11 & 1.16 & $0.60-2.23$ & 0.653 \\
\hline Unemployed & 13 & 8 & 1.27 & $0.60-2.71$ & 0.523 \\
\hline Farming & 14 & 28 & 0.38 & $0.21-0.69$ & $0.002^{*}$ \\
\hline Others & 28 & 26 & 0.90 & $0.53-1.52$ & 0.693 \\
\hline \multicolumn{6}{|l|}{ Religion } \\
\hline Orthodox & 94 & 95 & 1.00 & & \\
\hline Non-Orthodox & 6 & 5 & 1.20 & $0.52-2.78$ & 0.430 \\
\hline \multicolumn{6}{|l|}{$\begin{array}{l}\text { Income (Birr) per month } \\
\text { (US\$ } 1=\text { Birr 9) }\end{array}$} \\
\hline$\leq 99$ & 12 & 20 & 1.00 & & \\
\hline$>99$ & 88 & 80 & 1.80 & $1.06-3.08$ & $\begin{array}{l}0.029^{*} \\
\text { Contd. }\end{array}$ \\
\hline
\end{tabular}




\begin{tabular}{|c|c|c|c|c|c|}
\hline Characteristics & $\begin{array}{c}\text { Cases }(\%) \\
(\mathrm{n}=220)\end{array}$ & $\begin{array}{c}\text { Controls (\%) } \\
(\mathrm{n}=220)\end{array}$ & OR & CI & $\mathrm{p}$ value \\
\hline $\begin{array}{l}\text { Heard about health } \\
\text { education on child health } \\
\text { Source of information }\end{array}$ & 70 & 71 & 0.96 & $0.64-1.44$ & 0.837 \\
\hline Radio and/or TV & 59 & 60 & 1.04 & $0.71-1.52$ & 0.845 \\
\hline Health personnel & 62 & 56 & 0.77 & $0.51-1.14$ & 0.193 \\
\hline Friend, family, and others & 20 & 17 & 0.84 & $0.51-1.40$ & 0.523 \\
\hline \multicolumn{6}{|l|}{ Listen to radio } \\
\hline Yes & 74 & 76 & 1.00 & & \\
\hline No & 26 & 24 & 1.12 & $0.73-1.73$ & 0.583 \\
\hline Animals in compound & 36 & 40 & 0.81 & $0.52-1.27$ & 0.366 \\
\hline Child plays with animals & 19 & 17 & 0.99 & $0.56-1.69$ & 0.956 \\
\hline
\end{tabular}

known risk factors for diarrhoeal disease (Table 4). Multivariate analysis revealed that children whose mothers were farmers $(\mathrm{OR}=0.37$, $\mathrm{CI} 0.21-0.64)$ and who were breastfed and not completely weaned $(\mathrm{OR}=0.57$, CI 0.32-1.00) were protective factors; sharing drinking-water with 6-10 households $(\mathrm{OR}=1.65$, CI 1.05-2.58) and introducing supplemental foods $(\mathrm{OR}=2.64, \mathrm{CI} 1.25-5.60)$ were risk factors for diarrhoeal disease.

\section{Case management}

In terms of the clinical presentation of diarrhoea for cases, children aged 6-18 months were most susceptible to acute diarrhoea. Children presented with acute diarrhoea for 3.9 days [standard deviation (SD) 2.7] at the time of the interview with an average of 4.3 stools per day (SD 1.3). Twenty-eight percent of the children had 3 diarrhoeal stools per day, 63\% had 4-7 diarrhoeal stools per day, and $9 \%$ had 8 or more diarrhoeal stools per day. Seventeen percent of the cases had some signs of dehydration, and $9 \%$ of the children had severe dehydration as evaluated by interns using the WHO guidelines. Of $26 \%$ of the children with some or severe dehydration, 19\% were given intravenous fluids, and $14 \%$ were given antibiotics. There were no deaths in the study.

Mothers reported that $73 \%$ of the children with acute diarrhoea experienced an episode of vomiting during the illness. Mothers further reported that $70 \%$ of the cases had watery stool, $42 \%$ had mucous in the stool, and 19\% had blood in the stool. Lastly, only 3\% of the mothers took children with acute diarrhoea to a traditional healer during the episode.

\section{Food and fluid intake}

During diarrhoea episodes, mothers reported that $37 \%$ of the children ate bananas, $56 \%$ ate eggs,
$77 \%$ ate atmit, which is a wheat porridge, and $73 \%$ ate injera with shuro, which is the country's staple vegetarian food consisting of a pancake-like bread with bean stew. During the illness, mothers reported that $59 \%$ of the children received breastmilk, $68 \%$ received regular milk, $80 \%$ drank water, $76 \%$ drank tea, $11 \%$ drank rice-water, and $14 \%$ drank juice.

During episodes, $24 \%$ of the mothers gave less breastmilk, 34\% gave the same amount, and 13\% gave more breastmilk as usual. Fluids, defined as water, tea, rice-water, and juice, were withheld in $29 \%$ of the cases, were given the same amount in $44 \%$ of the cases, and were increased in $26 \%$ of the cases. Also, $46 \%$ of the mothers withheld food during the illness. Mothers withheld fluids more when the child vomited than if the child did not vomit during the illness (33\% vs $17 \%$ respectively, $\mathrm{p}=0.02$ ); the withholding of food was not associated with the presence of vomiting during the diarrhoea episode.

\section{Oral rehydration solution}

Before coming to the hospital, 9.5\% ( $\mathrm{n}=220)$ of cases with acute diarrhoea were given ORS in the home. Eighty-five percent $(n=220)$ of children with diarrhoea presenting to the University of Gondar Referral and Teaching Hospital were given a prescription for ORS. Eighty-three percent of cases with no dehydration (135/162) and $94 \%$ of cases with some dehydration (33/38) received a prescription for ORS. Additionally, $83 \%$ of the mothers knew how to prepare ORS, and $49 \%$ reported that their children had received ORS in the past.

\section{DISCUSSION}

Diarrhoeal disease represents a major killer among children aged less than five years in developing 


\begin{tabular}{|c|c|c|c|c|c|}
\hline Characteristics & $\begin{array}{c}\text { Cases }(\%) \\
(\mathrm{n}=220)\end{array}$ & $\begin{array}{c}\text { Controls } \\
(\%) \\
(\mathrm{n}=220)\end{array}$ & OR & $\mathrm{CI}$ & $\mathrm{p}$ value \\
\hline \multicolumn{6}{|l|}{ Place of child's last defaecation } \\
\hline Latrine & 4 & 3 & 1.00 & & \\
\hline Ground & 34 & 36 & 0.78 & $0.25-2.46$ & 0.682 \\
\hline Small bucket (Popo) & 41 & 39 & 0.87 & $0.29-2.62$ & 0.817 \\
\hline Underclothes & 21 & 21 & 0.84 & $0.24-2.89$ & 0.780 \\
\hline \multicolumn{6}{|l|}{ Disposal of stool } \\
\hline Child used latrine & 3 & 3 & 1.00 & & \\
\hline Put into latrine & 60 & 53 & 1.33 & $0.40-4.45$ & 0.639 \\
\hline Thrown in garbage & 21 & 20 & 1.21 & $0.35-4.18$ & 0.758 \\
\hline Buried & 2 & 3 & 0.60 & $0.09-3.72$ & 0.580 \\
\hline Left on ground & 15 & 20 & 0.86 & $0.24-3.03$ & 0.814 \\
\hline \multicolumn{6}{|l|}{ Disposal of water used for washing stool } \\
\hline Put in latrine & 40 & 35 & 1.00 & & \\
\hline Thrown on ground & 31 & 33 & 0.77 & $0.48-1.23$ & 0.277 \\
\hline Thrown in garbage & 0 & 2 & - & - & 0.990 \\
\hline No water used & 29 & 30 & 0.83 & $0.51-1.36$ & 0.468 \\
\hline Child plays in area of faeces & 28 & 22 & 1.40 & $0.89-2.21$ & 0.140 \\
\hline Washing of hands before preparing food & 99 & 98 & 1.00 & $0.20-4.95$ & 1.000 \\
\hline \multicolumn{6}{|l|}{ What used for hand-washing } \\
\hline Soap & 75 & 80 & 1.00 & & \\
\hline Only water & 25 & 20 & 1.37 & $0.87-2.17$ & 0.170 \\
\hline Soap available at home & 92 & 85 & 1.82 & 1.01-3.29 & $0.047^{*}$ \\
\hline \multicolumn{6}{|l|}{ Soap used for } \\
\hline Own body & 89 & 88 & 0.94 & $0.48-1.83$ & 0.866 \\
\hline Child & 88 & 87 & 0.95 & $0.50-1.80$ & 0.869 \\
\hline Hand & 84 & 87 & 0.78 & $0.42-1.45$ & 0.436 \\
\hline Food-utensils & 77 & 73 & 1.28 & $0.78-2.10$ & 0.319 \\
\hline Clothes & 96 & 92 & 2.33 & $0.90-6.07$ & 0.082 \\
\hline \multicolumn{6}{|l|}{ Hand-washing with soap when eating } \\
\hline Before taking food & 6 & 4 & 1.44 & $0.61-3.37$ & 0.396 \\
\hline After taking food & 1 & 1 & 1.50 & $0.25-8.97$ & 0.657 \\
\hline Both before and after taking food & 74 & 79 & 0.79 & $0.49-1.18$ & 0.229 \\
\hline \multicolumn{6}{|l|}{ Soap used } \\
\hline Before preparing food & 17 & 15 & 1.13 & $0.69-1.87$ & 0.612 \\
\hline After cleaning child's bottom & 29 & 22 & 1.40 & $0.90-2.16$ & 0.128 \\
\hline After using toilet & 33 & 29 & 1.22 & $0.78-1.89$ & 0.372 \\
\hline Child eats by himself/herself & 40 & 43 & 0.75 & $0.42-1.32$ & 0.319 \\
\hline Child washes before eating & 37 & 39 & 1.20 & $0.36-3.93$ & 0.763 \\
\hline
\end{tabular}




\begin{tabular}{|c|c|c|c|c|c|}
\hline Characteristics & $\begin{array}{c}\text { Cases (\%) } \\
(\mathrm{n}=220)\end{array}$ & $\begin{array}{c}\text { Controls } \\
(\%) \\
(\mathrm{n}=220)\end{array}$ & OR & $\mathrm{CI}$ & $\mathrm{p}$ value \\
\hline \multicolumn{6}{|l|}{ Water source } \\
\hline Protected spring & 5 & 11 & 0.39 & $0.18-0.84$ & $0.017^{*}$ \\
\hline All other water sources & 95 & 89 & 1.00 & & \\
\hline Number of minutes to fetch water & $9.2(9.4)^{\dagger}$ & $\begin{array}{c}13.1 \\
(18.5)^{\dagger}\end{array}$ & 0.97 & $0.95-0.99$ & $0.005^{*}$ \\
\hline Number of 20-L buckets & $2.7(1.3)^{\dagger}$ & $2.8(1.0)^{\dagger}$ & 0.91 & $0.77-1.07$ & 0.284 \\
\hline \multicolumn{6}{|l|}{ Storing water } \\
\hline Wide nozzle & 16 & 10 & 1.00 & & \\
\hline Narrow nozzle & 84 & 90 & 0.56 & $0.31-0.98$ & $0.042^{*}$ \\
\hline Shared water source with other households & 72 & 64 & 1.44 & $0.95-2.19$ & 0.080 \\
\hline \multicolumn{6}{|l|}{ Number of households sharing water source } \\
\hline Not share & 27 & 35 & 1.00 & & \\
\hline $1-5$ & 17 & 13 & 1.58 & $0.87-2.84$ & 0.128 \\
\hline $6-10$ & 17 & 11 & 1.94 & $1.04-3.63$ & $0.038^{*}$ \\
\hline $11-20$ & 9 & 6 & 1.76 & $0.75-4.11$ & 0.190 \\
\hline$>20$ & 28 & 33 & 1.06 & $0.65-1.34$ & 0.805 \\
\hline \multicolumn{6}{|l|}{ Method of pouring drinking-water } \\
\hline Pour directly & 91 & 93 & 1.00 & & \\
\hline Dip from bucket & 9 & 7 & 1.45 & $0.68-3.13$ & 0.339 \\
\hline Treat water & 4 & 2 & 2.00 & $0.60-6.64$ & 0.258 \\
\hline
\end{tabular}

Table 4. Risk factors in multivariate analysis, University of Gondar Referral and Teaching Hospital, 2007

\begin{tabular}{|lcc|}
\hline Characteristics & $\begin{array}{c}\text { Final model } \\
\text { OR }(95 \% \mathrm{CI})\end{array}$ & $\begin{array}{c}\text { SES-adjusted } \\
\text { OR }(95 \% \mathrm{CI})\end{array}$ \\
\hline Farmer & $0.37(0.21-0.64)$ & $0.45(0.24-0.84)$ \\
Sharing water source with & & \\
6-11 households & $1.65(1.05-2.58)$ & $1.79(1.12-2.85)$ \\
Supplemental feeding & $2.64(1.25-5.60)$ & $2.58(1.21-5.50)$ \\
Breastfed and not completely weaned & $0.57(0.32-1.00)$ & $0.55(0.31-0.99)$ \\
Maternal education $(\geq 9$ years) & - & $1.00(0.61-1.65)$ \\
Income (Birr $>99)$ & - & $1.62(0.86-3.07)$ \\
\hline CI=Confidence interval; OR=Odds ratio; SES=Socioeconomic status & \\
\hline
\end{tabular}

countries, yet deaths from this disease can be entirely prevented. To our knowledge, this is the largest case-control study in Ethiopia that considered a number of potential risk factors for acute diarrhoeal disease. We showed that occupation of mothers, children who were breastfed and not completely weaned, households sharing their water source, and introducing supplemental food had significant relationships with the occurrence of acute diarrhoea in Ethiopia.

\section{Comparison between cases and controls}

The higher socioeconomic status of the cases com- pared to the controls could be attributable to a study in Ethiopia, which documented that more urban mothers sought care outside the home for children with diarrhoea than with pneumonia or malaria (10).

\section{Breastfeeding and supplemental feeding}

Our finding that children who were breastfed had half the risk of acute diarrhoea than children who were not breastfed emphasizes how breastfeeding protects children from acute diarrhoea, which is in agreement with the results of previous studies from Africa, South America, and Asia (12-14). The role of age as an effect-modifier for the risk of acute di- 
arrhoea was emphasized in the present study. The risk of acute diarrhoea among breastfed children aged 7-12 months increased compared to other agegroups; however, Molbak et al. suggest that breastfeeding protects children against diarrhoea after infancy (15). The increased risk of diarrhoea among breastfed children aged 7-12 months coincides with the increased risk that we found among the same age-group who started food and fluids. We suggest that children who were breastfed and started food and fluids may have ingested pathogens during the weaning feeding period that would have not been present in breastmilk, thereby increasing the risk of acute diarrhoea (16).

A range of factors during the introduction of food and fluids may increase the risk of diarrhoea-factors that our study did not measure and may confirm our results. These factors include using foods of low energy and nutrient concentration, selecting single foods of low nutritional value, weaning abruptly, using contaminated foods, feeding at infrequent intervals, the preparation of food several hours before consumption combined with storage at ambient temperatures, and inadequately cooling and reheating foods $(17,18)$. Although mothers should continue to feed children during the weaning period and prepare, store, and handle foods under hygienic conditions, evidence is lacking demonstrating the efficacy about how educating mothers about food-hygiene practices can prevent or decrease acute diarrhoea.

Furthermore, we found that the risk of diarrhoea for children who have received food and fluid decreased as children grew and developed, which may be due to children developing immunity from repeated exposures to pathogens (19). Additionally, children aged 12-24 months who were breastfed may have been protected against acute diarrhoea due to antibodies and hormones present in breastmilk that can promote the proliferation of the gut mucosa and recovery from infection (20). There is evidence that the protective components of breastmilk increase during weaning (21). In contrast, breastfeeding after 12 months has been associated with reduced energy intake and malnutrition but we did not measure these variables in our study $(22,23)$. We demonstrate that there may be a protective effect of breastfeeding after infancy on acute diarrhoea but we cannot comment if mothers should breastfeed children after infancy because we did not measure the impact of breastfeeding on other infectious diseases, nutritional status of children, and child mortality.

\section{Farmer}

Children whose mothers were farmers had 0.37 the risk of acute diarrhoea compared to children whose mothers were not farmers. This association may be explained by the fact that Ethiopian mothers who farm are more likely to bring their children to the fields as they work, and, therefore, the farmers may have had more opportunities to breastfeed their children during the day and may breastfeed more frequently than mothers who had government jobs. This justification is supported by a study in Bangladesh, which found that farmers breastfed longer than women of other occupations (24) and a study from Guinea-Bissau, which suggested that the incidence of diarrhoea was lower among breastfed children compared to completely-weaned children due to the quantity of breastmilk consumed (12). Although the effects of breastfeeding on acute diarrhoea are well-known, the extent to which maternal occupation may influence the risk of acute diarrhoea is less understood.

\section{Water}

Studies have shown that water-treatment practices, such as boiling or filtration at the household, have a greater effect on the reduction of diarrhoea than improving the water source (25). On the other hand, our study revealed that children whose families shared the water source were more likely to develop diarrhoea than families who had their own water source but water-treatment practices were insignificant between the cases and the controls. Although we did not test the water sources for faecal contamination, sharing the water source with more households may create opportunities to contaminate the water source and could explain the higher risk of acute diarrhoea. In Nicaragua, Amador et al. found that sharing water source with neighbours tripled the risk that children died of diarrhoea (26). Interestingly, households in our study that shared water with 6-10 households had a higher risk of acute diarrhoea than households that shared water with more than 10 households. We suggest that information on various variables that we did not collect may explain this finding, such as hygiene practices during the collection of water, washing the container used for collecting water from the source, and covering the water-container. Additionally, storing drinking-water in a bucket with a narrow nozzle decreased the risk of diarrhoea, which supports evidence that narrow-mouthed water-storage vessels reduce contamination (27). Operations research to explore innovative methods to educate neighbours who share water source to reduce contamination at the source and to use narrow-mouthed storage vessels may be beneficial. 


\section{Case management}

The practice of giving less food and fluid to children with acute diarrhoea is a common occurrence that has been previously reported in Ethiopia (28) and in other developing countries $(29,30)$; however, the reasons why mothers are changing feeding behaviour are less understood. We found that children who vomited during the illness were associated with mothers giving less fluid but not less food, which concurs with the results from Zambia that found $65 \%$ of mothers completely stopped fluids if children vomited during a diarrhoea episode (30). This suggests that feeding behaviour of mothers may be influenced by the symptom of vomiting during diarrhoea episodes. Alternatively, mothers may be consciously withholding fluid as suggested from a study in Ethiopia where $73 \%$ of mothers thought that increased fluid intake worsens diarrhoea (28). More research is needed to determine the range of factors that prompt mothers to withdraw fluids during diarrhoea. Health educators should not only focus on improving knowledge of mothers about the use of ORT but also consider the nature of illness episodes that influences the mother's feeding of children with acute diarrhoea.

Mothers did not administer fluids at the first signs of diarrhoeal disease. We found that mothers visited the hospital approximately four days after the start of their child's illness, and less than $10 \%$ of the mothers reported giving ORS in the home during diarrhoea episodes. Interventions that educate mothers about the warning signs of diarrhoea may be able to improve care-seeking practices and increase fluid intake in the home and during illnesses. Mothers should be encouraged to follow the recommendations of WHO to increase breastmilk and fluid intake at the first signs of diarrhoea (31). An encouraging result in the promotion of homemade alternatives to ORS is that more than three of every four children with diarrhoea ate atmit, a home-made cereal-based ORS. A previous study found that home-made cereal-based ORS was an effective and culturally-accepted alternative to ORS in Ethiopia (32), suggesting that culturally-accepted alternatives to ORS may help further promote ORT.

\section{Limitations}

There are several limitations of the present study. First, the selection of controls with illnesses other than acute diarrhoea from the hospital may mean that our results may not be applicable to the general population. However, the majority $(56 \%)$ of the controls were identified at outpatient visits, with infectious diseases common to many otherwise healthy Ethiopian children, suggesting that the selection bias of controls in our study may be low. We might expect our results to underestimate the protective effect of breastfeeding in the general population, since good breastfeeding practices can reduce the risk of many infectious diseases. We would expect that the breastfeeding practices of our cases and controls are more similar to each other and not optimal. Also, since water exposure variables play a stronger role in acute diarrhoea than other infectious diseases in the control group, we would not expect the water exposure results to be much different if controls were population-based. On the other hand, the use of hospital-based controls has the advantage of controlling for variables relating to access to care, as both cases and controls overcame the same barriers to seek healthcare at the hospital regardless of where they lived.

Second, behaviours reported by the mothers were not observed in the households. Mothers are known to over-report desirable hygiene behaviours, which may explain why maternal caretaking exposure variables were not significant (33). Third, recall bias may occur as the mothers were recounting behaviours, the signs of diarrhoea and vomiting, and the frequency of diarrhoea episodes in their children (34). Fourth, the study was conducted at a referral hospital, which is often the last place caretakers turn to seek care for their children (35). Lastly, interns who interviewed mothers were busy managing children and occasionally missed questions on the survey but we immediately checked the questionnaire after completion and filled in the necessary gaps. Despite these limitations, our study contributes important information to the risk factors and management of acute diarrhoea.

\section{Conclusion}

Our study collected a range of exposure variables for acute diarrhoea in a developing country, which allowed for assessing the relative contribution of each exposure variable in the development of acute diarrhoea. Furthermore, the results from the case management of acute diarrhoea underscored how vomiting during diarrhoea episodes is linked to the withholding of fluid by mothers. Nevertheless, like all studies, our findings need to be interpreted with caution since they can be generalized to caretakers who seek care for children at hospitals in developing countries where acute diarrhoea is a prevalent childhood illness. The sample studied may not be representative of caretakers who decide not to seek treatment or are unable to seek treatment for acute diarrhoea at a referral hospital. On the other hand, 
our results are applicable when designing effective interventions in hospitals aimed at educating many caregivers about how to prevent acute diarrhoea and how to effectively manage the illness, opportunities that are often missed.

\section{ACKNOWLEDGEMENTS}

The authors are grateful to the Johns Hopkins Woodrow Wilson Research Fellowship and Grant No. 5R25TW007506 from the Fogarty International Center at the National Institutes of Health for financial support, the University of Gondar for allowing them to conduct the study at the hospital, the interns who collected the data, and the mothers attending the University of Gondar Referral and Teaching Hospital in Gondar for their cooperation during the study.

\section{REFERENCES}

1. Kosek M, Bern C, Guerrant RL. The global burden of diarrhoeal disease, as estimated from studies published between 1992 and 2000. Bull World Health Organ 2003;81:197-204.

2. Boschi-Pinto C, Velebit L, Shibuya K. Estimating child mortality due to diarrhoea in developing countries. Bull World Health Organ 2008;86:710-7.

3. Fontaine O, Kosek M, Bhatnagar S, Boschi-Pinto C, Chan KY, Duggan C et al. Setting research priorities to reduce global mortality from childhood diarrhoea by 2015. PLoS Med 2009;6:e41.

4. Duggan C, Santosham M, Glass RI. The management of acute diarrhea in children: oral rehydration, maintenance, and nutritional therapy. Centers for Disease Control and Prevention. MMWR Recomm Rep 1992;41(RR-16):1-20.

5. King CK, Glass R, Bresee JS, Duggan C. Managing acute gastroenteritis among children: oral rehydration, maintenance, and nutritional therapy. $M M W R$ Recomm Rep 2003;52(RR-16):1-16.

6. Victora CG, Bryce J, Fontaine O, Monasch R. Reducing deaths from diarrhoea through oral rehydration therapy. Bull World Health Organ 2000;78:1246-55.

7. Ethiopia. Central Statistical Authority. Ethiopia: demographic and health survey 2005. Addis Ababa: Central Statistical Authority, 2006:13-36,127-41.

8. Dupont WD, Plummer WD, Jr. Power and sample size calculations. A review and computer program. Control Clin Trials 1990;11:116-28.

9. World Health Organization. Management of the child with a serious infection or severe malnutrition: guidelines for care at the first-referral level in developing countries. Geneva: World Health Organization, 2000:45-9.
10. Andrade IG, Queiroz JW, Cabral AP, Lieberman JA, Jeronimo SM. Improved sanitation and income are associated with decreased rates of hospitalization for diarrhoea in Brazilian infants. Trans $R$ Soc Trop Med Hyg 2009;103:506-11.

11. Mahalanabis D, Faruque AS, Islam A, Hoque SS. Maternal education and family income as determinants of severe disease following acute diarrhoea in children: a case control study. J Biosoc Sci 1996;28:12939.

12. Mølbak K, Jensen H, Ingholt L, Aaby P. Risk factors for diarrheal disease incidence in early childhood: a community cohort study from Guinea-Bissau. Am J Epidemiol 1997;146:273-82.

13. Maranhão HS, Medeiros MC, Scaletsky IC, FagundesNeto U, Morais MB. The epidemiological and clinical characteristics and nutritional development of infants with acute diarrhoea, in north-eastern Brazil. Ann Trop Med Parasitol 2008;102:357-65.

14. Mitra AK, Rabbani F. The importance of breastfeeding in minimizing mortality and morbidity from diarrhoeal diseases: the Bangladesh perspective. J Diarrhoeal Dis Res 1995;13:1-7.

15. Mølbak K, Gottschau A, Aaby P, Højlyng N, Ingholt L, da Silva AP. Prolonged breast feeding, diarrhoeal disease, and survival of children in Guinea-Bissau. BMJ 1994;308:1403-6.

16. Dewey KG, Adu-Afarwuah S. Systematic review of the efficacy and effectiveness of complementary feeding interventions in developing countries. Matern Child Nutr 2008;4(Suppl 1):24-85.

17. Ashworth A, Feachem RG. Interventions for the control of diarrhoeal diseases among young children: weaning education. Bull World Health Organ 1985;63:1115-27.

18. Motarjemi Y. Research priorities on safety of complementary feeding. Pediatrics 2000;106:1304-5.

19. Motarjemi Y, Käferstein F, Moy G, Quevedo F. Contaminated weaning food: a major risk factor for diarrhoea and associated malnutrition. Bull World Health Organ 1993;71:79-92.

20. Pathela P, Hasan KZ, Roy E, Huq F, Siddique AK, Sack RB. Diarrheal illness in a cohort of children 0-2 years of age in rural Bangladesh: I. Incidence and risk factors. Acta Paediatr 2006;95:430-7.

21. Goldman AS, Goldblum RM, Garza C, Nichols BL, Smith EO. Immunologic components in human milk during weaning. Acta Paediatr Scand 1983;72:133-4.

22. Victora CG, Vaughan JP, Martines JC, Barcelos LB. Is prolonged breast-feeding associated with malnutrition? Am J Clin Nutr 1984;39:307-14. 
23. Brakohiapa LA, Yartey J, Bille A, Harrison E, Quansah E, Armar MA et al. Does prolonged breastfeeding adversely affect a child's nutritional status? Lancet 1988;2:416-8.

24. Mannan HR, Islam MN. Breast-feeding in Bangladesh: patterns and impact on fertility. Asia Pac Popul J 1995;10:23-38.

25. Fewtrell L, Kaufmann RB, Kay D, Enanoria W, Haller L, Colford JM, Jr. Water, sanitation, and hygiene interventions to reduce diarrhoea in less developed countries: a systematic review and meta-analysis. Lancet Infect Dis 2005;5:42-52.

26. Amador JJ, Vicari A, Turcios-Ruiz RM, Melendez DAC, Malek M, Michel F et al. Outbreak of rotavirus gastroenteritis with high mortality, Nicaragua, 2005. Rev Panam Salud Publica 2008;23:277-84.

27. Pinfold JV. Faecal contamination of water and fingertip-rinses as a method for evaluating the effect of lowcost water supply and sanitation activities on faecooral disease transmission. II. A hygiene intervention study in rural north-east Thailand. Epidemiol Infect 1990;105:377-89.

28. Olango P, Aboud F. Determinants of mothers' treatment of diarrhea in rural Ethiopia. Soc Sci Med 1990; 31:1245-9.

29. Zodpey SP, Deshpande SG, Ughade SN, Kulkarni SW,
Shrikhande SN, Hinge AV. A prediction model for moderate or severe dehydration in children with diarrhoea. J Diarrhoeal Dis Res 1999;17:10-6.

30. Ng'andu NH, Nkowane BM. The management of diarrhoea in young children in a rural community in Zambia. J Trop Med Hyg 1988;91:199-201.

31. World Health Organization. Clinical management of acute diarrhoea. Geneva: World Health Organization, 2004:4.

32. Kassaye M, Larson C, Carlson D. A randomized community trial of prepackaged and homemade oral rehydration therapies. Arch Pediatr Adolesc Med 1994; 148:1288-92.

33. Manun'Ebo M, Cousens S, Haggerty P, Kalengaie M, Ashworth A, Kirkwood B. Measuring hygiene practices: a comparison of questionnaires with direct observations in rural Zaïre. Trop Med Int Health 1997;2:1015-21.

34. Melo MC, Taddei JA, Diniz-Santos DR, May DS, Carneiro NB, Silva LR. Incidence of diarrhea: poor parental recall ability. Braz J Infect Dis 2007;11:571-9.

35. Källander K, Hildenwall H, Waiswa P, Galiwango E, Peterson S, Pariyo G. Delayed care seeking for fatal pneumonia in children aged under five years in Uganda: a case-series study. Bull World Health Organ 2008;86:332-8. 